\title{
Perancangan Aplikasi Media Pembelajaran Jarimatika Penjumlahan dan Pengurangan Berbasis Multimedia
}

\author{
Andrian Syahputra', Dedek Indra Gunawan Hts ${ }^{2}$, Samsir ${ }^{3}$ \\ ${ }^{1}$ Univesitas Potensi Utama, Medan, Indonesia \\ ${ }^{2}$ Univesitas Potensi Utama, Medan, Indonesia \\ ${ }^{3}$ Univesitas Alwashliyah Labuhanbatu,Indonesia
}

\begin{tabular}{|c|c|}
\hline Info Artikel & Abstract \\
\hline Article history: & $\begin{array}{l}\text { The development of technology for learning media is now growing } \\
\text { rapidly. Lots learning activities that can be supported are more effective, }\end{array}$ \\
\hline Received: 21122018 & easy to learn and fun by using technology, learning to count in children \\
\hline Revised: 13012019 & needs to be improved so that the learning techniques of arithmetic are still \\
\hline Accepted: 28012019 & $\begin{array}{l}\text { monotonous, and easily cause boredom, so that learning like that can be } \\
\text { resolved into a learning process. effective, easy to learn and fun. The }\end{array}$ \\
\hline Kata Kunci: & $\begin{array}{l}\text { method used is Jarimatika, which is a method of counting using your } \\
\text { fingers. The high public interest in Jarimatika is a great potential for }\end{array}$ \\
\hline Media Pembelajaran & Jarimatika to be appointed as other suitable media for children. By \\
\hline Jarimatika & utilizing multimedia technology, the application of Jarimatika learning \\
\hline Multimedia & $\begin{array}{l}\text { media makes it easier to understand because in multimedia there are } \\
\text { images, animation, sound and video that summarize into an effective and }\end{array}$ \\
\hline Penulis Korespondensi: & interactive information. Learning to count adding and subtracting fingers \\
\hline andriansyahputra4@gmail.com & $\begin{array}{l}\text { with multimedia-based learning media makes children understand addition } \\
\text { and subtraction faster. }\end{array}$ \\
\hline
\end{tabular}

\begin{abstract}
Abstrak
Perkembangan Teknologi terhadap media pembelajaran kini semakin berkembang pesat. Banyak kegiatan pembelajaran yang bisa didukung menjadi lebih efektif, mudah dipelajari dan menyenangkan dengan menggunakan teknologi, Pembelajaran berhitung pada anak - anak perlu ditingkatkan sehingga teknik pembelajaran ilmu berhitung yang masih monoton, dan mudah menimbulkan rasa bosan, sehingga pembelajaran seperti itu bisa teratasi menjadi sebuah pembelajaran yang efektif, mudah dipelajari dan menyenangkan. Metode yang digunakan adalah Jarimatika yaitu salah satu metode berhitung dengan menggunakan jari tangan. Minat masyarakat yang tinggi terhadap Jarimatika merupakan potensi yang besar bagi Jarimatika untuk diangkat menjadi media lain yang sesuai bagi anak. Dengan memanfaatkan teknologi Multimedia membuat aplikasi media pembalajaran jarimatika lebih mudah dipahami karena didalam multimedia terdapat gambar, animasi, suara dan video yang merangkum menjadi sebuah informasi efektif dan interaktif. Belajar berhitung jarimatika penjumlahan dan pengurangan dengan media pembejaran berbasis multimedia membuat anak akan lebih cepat mengerti tentang penjumlahan dan pengurangan.
\end{abstract}

\section{PENDAHULUAN}

Sebagai pendukung keberhasilan metode pembelajaran, guru harus bisa menggunakan mediapembelajaran yang tepat yaitu alat bantu pembelajaran yang digunakan sesuai dengan tujuan dan isi materi pembelajaran sebagai usaha untuk mempermudah menyampaikan informasi dari sumber belajar kepada penerima informasi,[1] dengan tujuan untuk memperoleh hasil belajar yang lebih baik dalam kegiatan belajar mengajar.[2] Penggunaan media pembelajaran yang tidak sesuai mengakibatkan materi tidak tersampaikan dengan sempurna. Pemilihan media pembelajaran harus memperhatikan kondisi siswa sebagai subjek pembelajaran.[3] 
Metode berhitung jarimatika ini ditemukan oleh Septi Peni Wulandani, seorang ibu rumah tangga yang berhasil menciptakan metode berhitung menggunakan media jari yang disebut jarimatika. Metode ini berhasil mempermudah anak-anak untuk belajar berhitung dan memperkenalkan kepada anak sebagai suatu metode berhitung yang mudah di pahami dan mudah diterapkan.[4]

\section{KAJIAN LITERATUR}

\section{Media Pembelajaran}

Kata media berasal dari bahasa Latin dan merupakan bentuk jamak dari kata “medium”, yang berarti perantara atau pengantar. Media adalah perantara atau pengantar pesan dari si pengirim (komunikator atau sumber/source) kepada si penerima (komunikan atau audience/receiver). [4]

Sedang menurut KBBI, media dapat diartikan sebagai perantara, penghubung; alat (sarana) komunikasi seperti koran, majalah, radio, televisi, film, poster, dan spanduk, yang terletak diantara dua pihak (orang, golongan, dan sebagainya).[5] Jadi, secara umum bisa diartikan bahwa media pembelajaran adalah alat bantu proses belajar mengajar. Yaitu segala sesuatu yang dapat dipergunakan untuk merangsang pikiran, perasaan, perhatian dan kemampuan atau ketrampilan pelajar sehingga dapat mendorong terjadinya proses belajar pada peserta didik (siswa/murid).[6]

\section{Jarimatika}

Penemuan Jarimatika berasal dari kepedulian seorang ibu terhadap materi pendidikan anakanaknya. Septi Peni Wulandani lulusan sarjana Undip tahun 1995.Jarimatika adalah cara menghitung cepat penjumlahan dan pengurangan dalam mata peajaran matematika dasar dengan menggunakan jari tangan.[7] Jarimatika dapat sangat membantu ketika mengerjakan perhitungan dasar matematika dengan batasan waktu yang singkat. Jarimatika juga dapat membuat anak menjadi lebih imajinatif, ketika anak sudah menguasai jarimatika otak mereka akan dapat membayangkan jari-jari tangan mereka dan kemudian menghitung penjumlahan dan pengurangan.[8]

\section{Multimedia}

Multimedia adalah sebuah perubahan cara berkomunikasi satu sama lain. Misalkan dalam hal mengirim dan menerima informasi, [6]kini lebih efektif dilakukan dan lebih mudah di pahami dengan hadirnya elemen-elemen multimedia kini telah memperkuat informasi yang di dapatkan. Mulrimedia adalah penggunaan berbagai jenis media (teks, suara, grafik, animasi dan video) untuk menyampaikan informasi, kemudian ditambahkan elemen atau komponen interaktif.[9]

Definisi multimedia menurut beberapa ahli :

1. Rosch, multimedia adalah kombimasidari komputer dan vidio.

2. Mccomick, multimedia adalah gabungan dari 3elemen:suara, gambar, dan teks.

3. Robin dan linda multimedia adalah alat yang dapat menciptakan presentasi yang dinamis dan interaktif yang mengkombinasikan teks, grafik, animasi, audio dan vidio.

\section{III.PEMBAHASAN}

\section{Mengenal Jarimatika}

Dalam pelajaran jarimatika semua jari berfungsi untuk menghasilkan penjumlahan. Agar memudahkan pemahaman fungsi jari dibagi 2 yaitu, jari - jari tangan kanan melambangkan nilai kurang dari 10 (1 - 9) sedangkan jari - jari tangan kiri melambangkan nilai lebih dari 10.

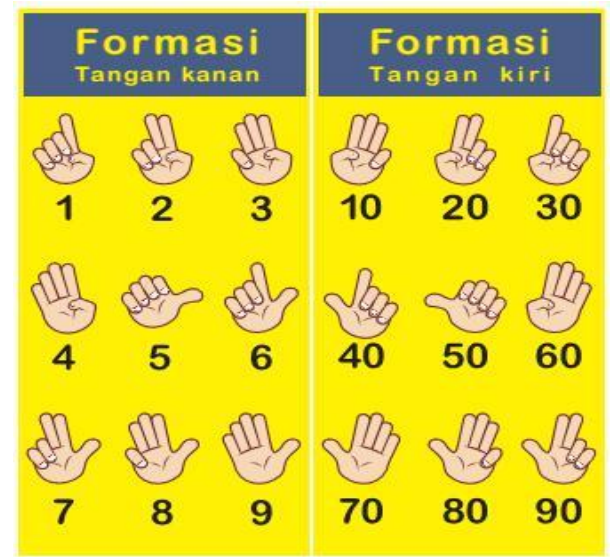




\section{Teman Kecil}

\section{Teman Kecil di Penjumlahan}

Teman-teman Kecil adalah dua bilangan yang jumlahnya

5. Mereka senang dapat saling menolong. Mereka tidak pernah berganti-ganti pasangan. Mereka setia satu dengan yang lain.

Mari kita kenali pasangan yang akrab ini.

Teman kecil 1 adalah 4

Teman kecil 2adalah 3

Teman kecil 3 adalah 2

Teman kecil 4adalah 1

Mereka selalu tahu bila temannya sedang dalam kesulitan. Dan mereka akan segera muncul untuk enolongnya, tanpa diminta.

$+4=(-1)+5$ [tambah 4 dioperasikan sebagai kurang 1 tambah 5]

$+3=(-2)+5$ [tambah 3 dioperasikan sebagai kurang 2 tambah 5]

$+=(-3)+5$ [tambah 2 dioperasikan sebagai kurang 3 tambah 5]

$+1=(-4)+5$ [tambah 1 dioperasikan sebagai kurang 4 tambah 5]

Contoh :

$3+4=$

Formasi Jarimatikanya adalah...

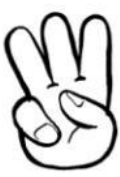

Dibaca: Tambah 3 BUKA

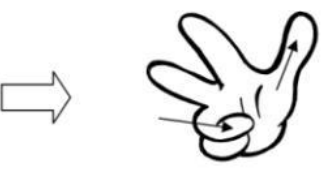

[Remudian baca dengan lancar tanpa jeda]: (Tambah empat) Kurang satu TUTUP tambah lima BUKA, oke

Dan hasilnya adalah 7.

[Perhatikan bahwa teman kecil 4 adalah 1 operasi yang dijalankan adalah $(-1)+5$, dibaca "Kurang satu TUTUP tambah lima BUKA"]

Teman Kecil di Pengurangan

$-4=(+1)-5$ [kurang 4 dioperasikan sebagai tambah 1 kurang 5]

$-3=(+2)-5$ [kurang 3 dioperasikan sebagai tambah 2 kurang 5]

$-2=(+3)-5$ [kurang 2 dioperasikan sebagai tambah 3 kurang 5]

$-1=(+4)-5$ [kurang 1 dioperasikan sebagai tambah 4 kurang 5]

Contoh :

$7-3=$

Formasi Jarimatika :
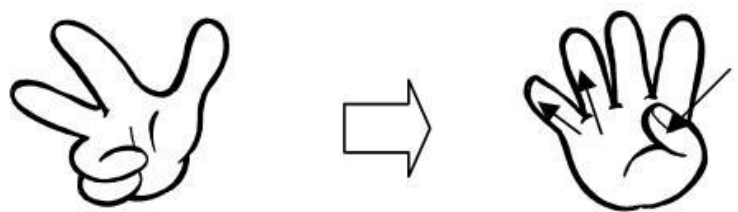

Dibaca : Tambah tujuh BUKA, (kurang tiga) tambah dua BUKA kurang lima TUTUP, Hasilnya adalah ... 4. 


\section{Teman Besar}

selanjutnya dengan TEMAN BESAR, yaitu Dua bilangan yang jumlahnya 10 adalah Teman Besar satu dengan yang lain.

Untuk TEMAN BESAR ini kita sudah memakai kedua tangan kita untuk membedakan nilai tempat masingmasing bilangan. Tangan KANAN sebagai

SATUAN dan tangan KIRI sebagai PULUHAN.

Ini dia pasangan setia berikutnya...

Teman Besar 1 adalah 9

Teman Besar 2 adalah 8

Teman Besar 3 adalah 7

Teman Besar 4 adalah 6

Teman Besar 5 adalah 5

Teman Besar 6 adalah 4

Teman Besar 7 adalah 3

Teman Besar 8 adalah 2

Teman Besar 9 adalah 1

meski tak persis sama - bahwa Teman Besar akan muncul saat diperlukan seperti halnya Teman Kecil.

Angka 1 - 4 adalah angka yang supel, karena mereka memiliki dua teman yaitu Teman Kecil dan Teman Besar. Bagaimana membedakannya?

Untuk penambahan, lihat faktor yang ditambah, kalau angka yang digunakan antara 6 - 9 berarti pakai teman besar, kalau antara $1-4$ berarti pakai teman kecil. Sedangkan untuk pengurangan, lihat faktor yang dikurang, bila angka yang digunakan 10 ke atas berati pakai teman besar, bila 10 ke bawah berarti pakai teman kecil.

Berikutnya kita akan masuk ke penggunaannya...

Teman Besar dalam Penambahan

$+9=(-1)+10$ [tambah 9 dioperasikan sebagai kurang 1 tambah 10]

$+8=(-2)+10$ [tambah 8 dioperasikan sebagai kurang 2 tambah 10]

$+7=(-3)+10$ [tambah 7 dioperasikan sebagai kurang 3 tambah 10]

$+6=(-4)+10$ [tambah 6 dioperasikan sebagai kurang 4 tambah 10]

$+5=(-5)+10$ [tambah 5 dioperasikan sebagai kurang 5 tambah 10]

$+4=(-6)+10$ [tambah 4 dioperasikan sebagai kurang 6 tambah 10]

$+3=(-7)+10$ [tambah 3 dioperasikan sebagai kurang 7 tambah 10]

$+2=(-8)+10$ [tambah 2 dioperasikan sebagai kurang 8 tambah 10]

$+1=(-9)+10$ [tambah 1 dioperasikan sebagai kurang 9 tambah 10]

Contoh :

$9+3=$

Formasi Jarimatika
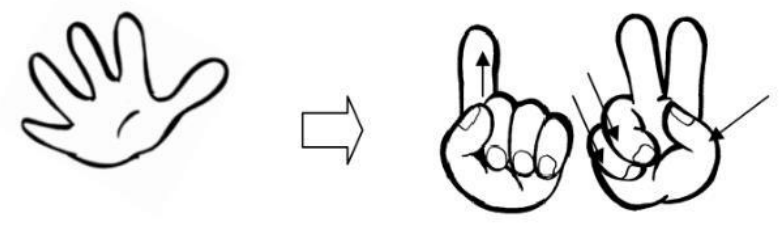

Dibaca : Tambah sembilan BUKA, (tambah tiga) kurang tujuh TUTUP tambah sepuluh BUKA, Hasilnya dapat kita lihat yaitu 12 .

U-NET Jurnal Teknik Informatika, Vol. 03, No. 01, Februari 2019: 35 - 42 
Teman Besar dalam pengurangan

$-9=(+1)-10$ [kurang 9 dioperasikan sebagai tambah 1 kurang 10]

$-8=(+2)-10$ [kurang 8 dioperasikan sebagai tambah 2 kurang 10]

$-7=(+3)-10$ [kurang 7 dioperasikan sebagai tambah 3 kurang 10]

$-6=(+4)-10$ [kurang 6 dioperasikan sebagai tambah 4 kurang 10]

$-5=(+5)-10$ [kurang 5 dioperasikan sebagai tambah 5 kurang 10]

$-4=(+6)-10$ [kurang 4 dioperasikan sebagai tambah 6 kurang 10]

$-3=(+7)-10$ [kurang 3 dioperasikan sebagai tambah 7 kurang 10]

$-2=(+8)-10$ [kurang 2 dioperasikan sebagaitambah 8 kurang 10]

$-1=(+9)-10$ [kurang 1 dioperasikan sebagai tambah 9 kurang 10]

Contoh :

$22-9=$.

Formasi jarimatika :
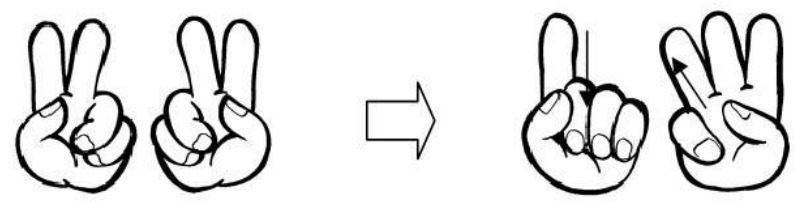

Dibaca: Tambah duapuluh dua BUKA, (kurang sembilan) tambah satu BUKA kurang sepuluh TUTUP,

hasilnya....13

\section{HASIL DAN PERANCANGAN}

\section{Tampilan Depan}

Tampilan awal ketika aplikasi dijalankan, ditampilan depan terdapat tombol mulai yang berguna untuk masukkan halaman berikutnya.

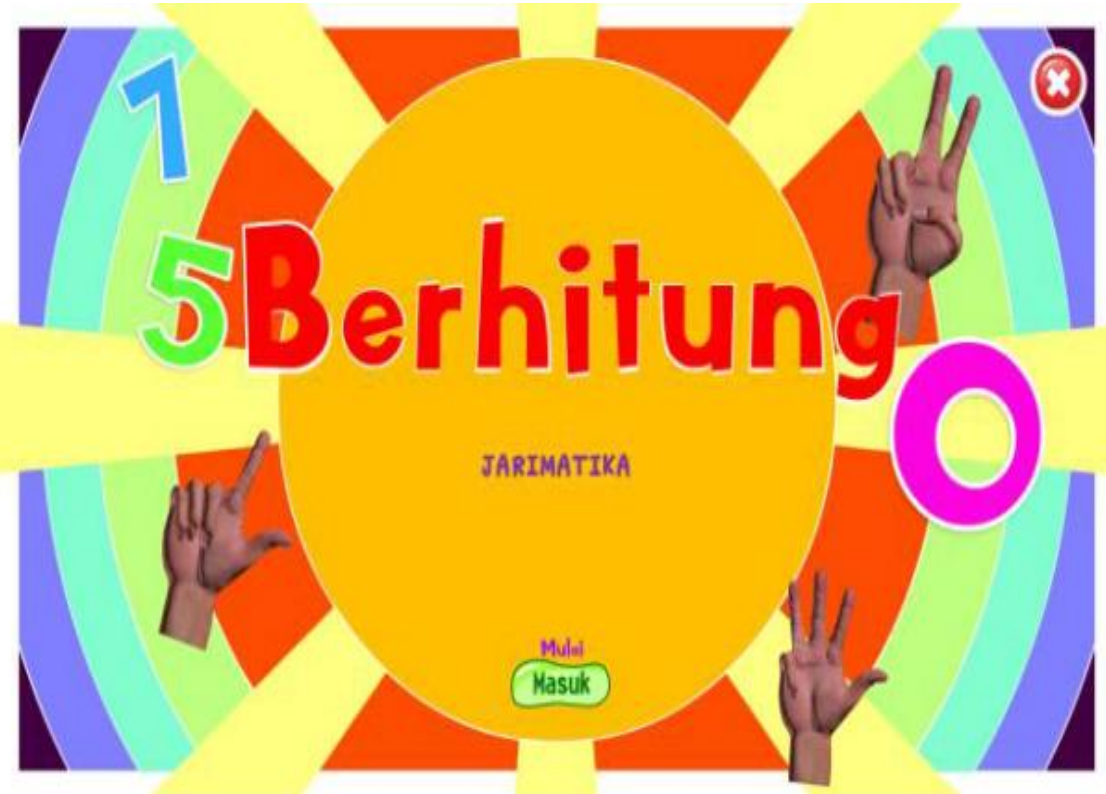




\section{Tampilan Menu}

Di tampilan halaman ini menampilkan 3 tombol, yaitu tombol Pengenalan Jarimatika, Latihan Berhitung dan Kuis jarimatika.

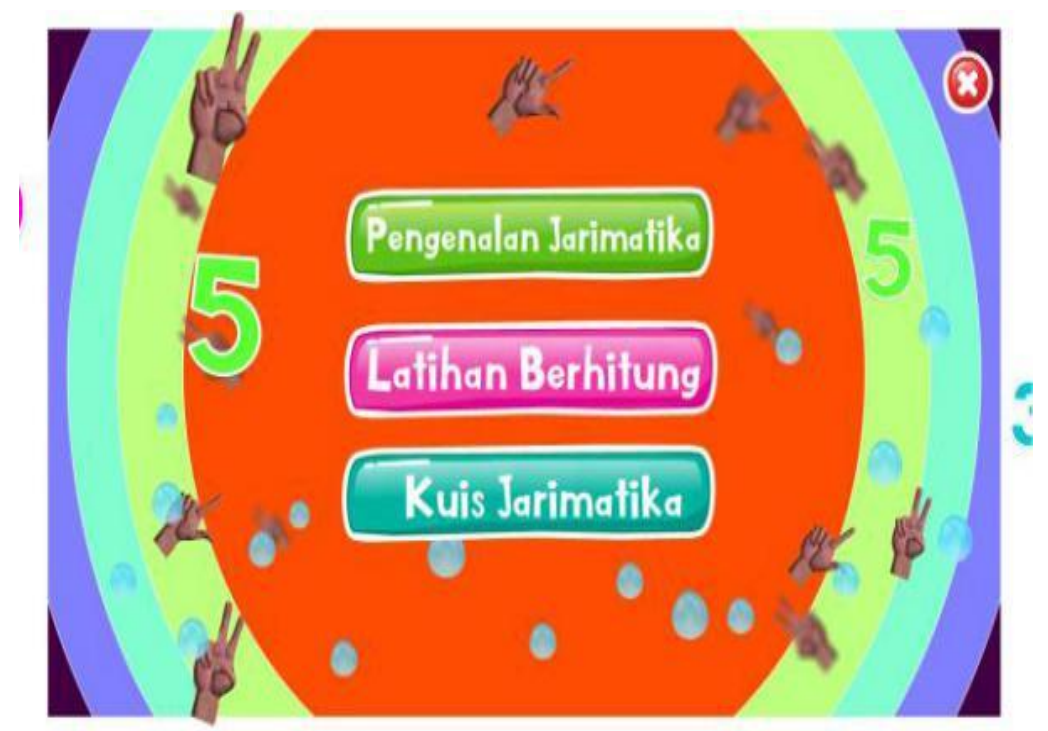

3. Tampilan Latihan Berhitung

Di halaman ini terdapat 2 tombol, yaitu tombol Penjumlahan dan Pengurangan.

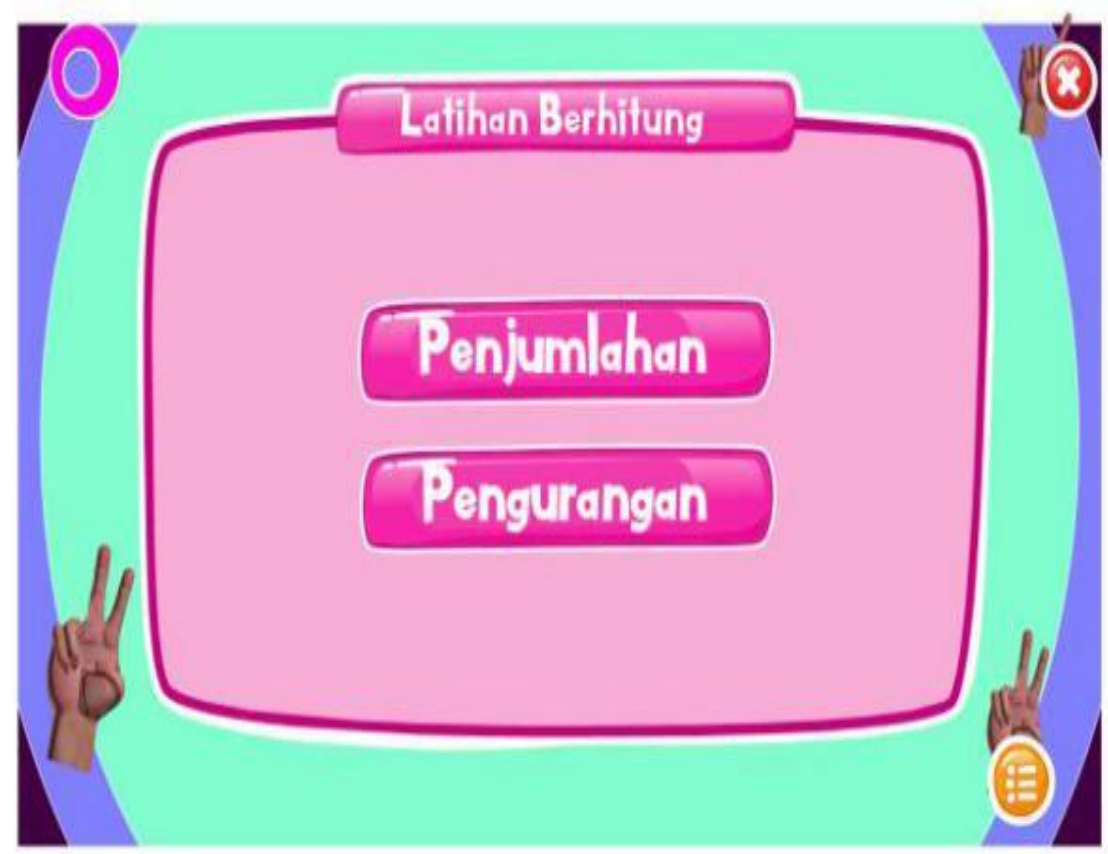


4. Tampilan Kuis Jarimatika

Dihalaman ini menampilkan 3 tombol, yaitu tombol Menebak Jumlah, Latihan Menjumlahkan dan Latihan Pengurangan.

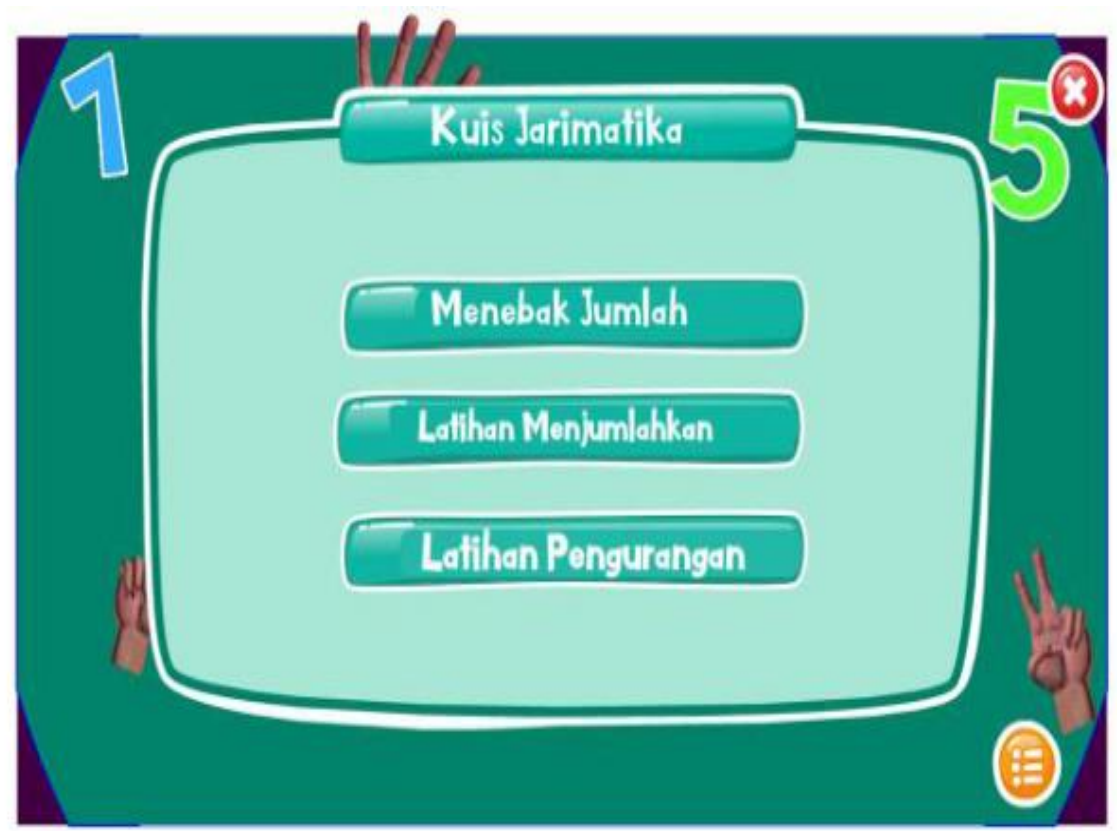

\section{KESIMPULAN DAN SARAN}

\section{Kesimpulan}

Berdasarkan hasil penelitian yang telah di uraikan maka kesimpulan dari penelitianini adalah :

1. Media pembelajaran ini bisa dijadikan alternatif untuk mengenal lebih jauh tentang teknik berhitung menggunakan metode jarimatika.

2. Membuat minat belajar siswa lebih aktif dalam materi perhitungan terutama perkalian dan pengurangan.

3. Aplikasi ini dibangun dengan menggunakan gabungan suara, teks dan gambar, sehingga diharapkan user bisa lebih memahami dan lebih tertarik dalam mempelajari metode Jarimatika.

4. Aplikasi ini berbasis dekstop bertujuan sebagai media pembelajaran berhitung menggunakan jari tangan dalam menerapkan metode Jarimatika.

5. Aplikasi ini bisa digunakan sebagai media pembelajaran untuk siswa.

\section{SARAN}

Perancangan dan penerapan media pembelajran ini dalam proses pembelajaran memiliki beberapa saran antara lain :

1. Sebaiknya media pembelajaran ini dikembangkan agar mampu memberikan informasi yang lebih mendalam tentang teknik berhitung menggunakan metode jarimatika.

2. Pada tampilan video animasi ini masih kurang mendetail sehingga perlu penambahan terhadap fitur animasi sehingga pengguna memperoleh informasi yang jelas.

3. Untuk kedepannya media pembelajaran ini dapat di akses melalui internet. 


\section{REFERENSI}

[1] R. Watrianthos, Y. Triyanto, P. Pristiyono, D. Hasibuan, and S. Samsir, "e-Government Village Model,” 2020, doi: 10.4108/eai.11-12-2019.2290857.

[2] Syaiful Zuhri Harahap and Samsir, "Application Design The Data Collection Features of The Hotel Shades of Rantauprapat Using VBNET,” Int. J. Sci. Technol. Manag., 2020, doi: 10.46729/ijstm.v1i1.4.

[3] S. Zulkifli, "Implementasi Sistem Keamanan SQL Injection Dalam berbasis web," Ejurnal.Univalabuhanbatu.Ac.Id, vol. 04, no. 01, pp. 13-17, 2020, [Online]. Available: https://ejurnal.univalabuhanbatu.ac.id/index.php/u-net/article/download/164/130.

[4] U. Verawardina, F. Edi, and R. Watrianthos, "Analisis Sentimen Pembelajaran Daring Pada Twitter di Masa Pandemi COVID-19 Menggunakan Metode Naïve Bayes,” vol. 5, pp. 157-163, 2021, doi: 10.30865/mib.v5i1.2604.

[5] J. H. P. Sitorus et al., "Perancangan pengontrol lampu rumah miniatur dengan menggunakan micro controler arduino berbasis android 1," vol. 4, no. 1, pp. 1-11, 2020.

[6] Samsir, D. I. G. Hts, and S. Z. Harahap, "SPK Untuk Pemilihan Kepala Sekolah Menggunakan Metode Saw dan Profile Matching," U-NET J. Tek. Inform., 2020.

[7] Samsir and Syaiful Zuhri Harahap, "Application Design Resume Medical By Using Microsoft Visual Basic. Net 2010 At the Health Center Appointments," Int. J. Sci. Technol. Manag., vol. 1, no. 1, pp. 14-20, 2020, doi: 10.46729/ijstm.v1i1.5.

[8] Samsir, "Klasifikasi Penyakit Tenggorokan Hidung Telinga ( THT ) Menggunakan Jaringan Syaraf Tiruan Dengan Metode Learning Vektor Quantization ( THT ) Di RSUD Rantauprapat Labuhanbatu Klasifikasi penyakit Tenggorokan Hidung Telinga ( THT ) Menggunakan,” vol. 05, no. 01, pp. 38 47, 2019.

[9] M. V. B. Net, "PADA TOKO URIP MOTOR,” no. September, pp. 1-6, 2020.

[10] D. I. G. H. Wirhan Fahrozi, Samsir, "Penerapan E-Commerce Pada Toko Bunga Underwear," J. Tek. Inform., vol. 04, no. 01, pp. 1-6, 2020.

[11] S. Samsir, S. Suparno, and M. Giatman, "Predicting the loan risk towards new customer applying data mining using nearest neighbor algorithm," IOP Conf. Ser. Mater. Sci. Eng., vol. 830, no. 3, 2020, doi: 10.1088/1757-899X/830/3/032004.

[12] R. A. Purba, S. Samsir, M. Siddik, S. Sondang, and M. F. Nasir, "The optimalization of backpropagation neural networks to simplify decision making," IOP Conf. Ser. Mater. Sci. Eng., vol. 830, no. 2, 2020, doi: 10.1088/1757-899X/830/2/022091.

[13] W. Fahrozi, P. T. Informatika, T. Informatika, F. U. A. Labuhanbatu, T. Mulia, and K. Medan, "UNET : Jurnal Teknik Informatika LPPM - Universitas Al Washliyah Labuhanbatu 23 | P a g e UNET : Jurnal Teknik Informatika Sebagai langkah awal yang dilakukan supaya dapat mengetahui gambaran permasalahan yang dihadapi dalam menentukan rasa yam serama a," vol. 3, no. 5, pp. 2327, 2019.

[14] M. Siddik and S. Samsir, "Rancang Bangun Sistem Informasi Pos (Point of Sale) Untuk Kasir Menggunakan Konsep Bahasa Pemrograman Orientasi Objek,” JOISIE (Journal Inf. Syst. Informatics Eng., vol. 4, no. 1, p. 43, 2020, doi: 10.35145/joisie.v4i1.607.

[15] P. T. Informatika and F. U. A. Labuhanbatu, "U-NET : Jurnal Teknik Informatika LPPM Universitas Al Washliyah Labuhanbatu 18 |P a g e U-NET : Jurnal Teknik Informatika Sebagai langkah awal yang dilakukan supaya dapat mengetahui gambaran permasalahan yang dihadapi oleh bagian kesiswaan adalah denga," vol. 3, no. 4, pp. 18-22, 2019. 